\title{
Naturalness and Artificiality Revisited Through Natural Infinity ${ }^{1}$
}

\author{
Jan Romportl \\ Katedra filozofie \\ Filozofická fakulta \\ Západočeská univerzita \\ Univerzitní 2732/8, 30100 Plzeň \\ romportl@me.com
}

\begin{abstract}
Discussions about naturalness, artificiality and unnaturalness in this article are motivated by the field of Human Cognitive Enhancement (HCE) because of its potential for altering human personality and identity. This article at first proposes a concept of human naturalness as interaction between physis and logos. Then it presents an intuitive understanding of naturalness in terms of the inherent inability of language to fully describe all attributes of an object that is natural. The analytical core of the article proposes a formal model of naturalness utilising Vopenka's phenomenologically grounded Alternative Set Theory (AST), comprising and formalising the concept of natural infinity. A brief introduction to AST is presented as well. Naturalness and artificiality are modelled as two structurally different naturally infinite semisets within AST. This key structural difference is then analysed and applied back to the domain of HCE.
\end{abstract}

Key words: naturalness, artificiality, infinity, logos, physis, philosophy of language, human cognitive enhancement, alternative set theory, semiset, bioethics

\section{Introduction}

The contribution of this article to the theoretical analysis of the concepts of natural, artificial and unnatural is motivated by research in the field of Human Cognitive Enhancement (HCE). This article has been written

1 The research leading to these results has received funding from the Norwegian Financial Mechanism 2009-2014 and the Ministry of Education, Youth and Sports of the Czech Republic under Project Contract no. MSMT-28477/2014, Project no. 7F14236. 
in the broader context of a transdisciplinary research project that aims at a complex assessment of the whole range of HCE-related issues, questions, and aspects, including an experimental analysis with neuroimaging and psycho-cognitive testing, health risks and benefits, public acceptance, and bioethical grounding. Especially the latter are very much influenced by discussions about naturalness - whether extending and enhancing human cognition by various technological interventions is natural or unnatural, and whether this is related to how good or bad and how acceptable or unacceptable such interventions are. However, in many of these discussions, it is very often left completely aside what the concept of natural actually refers to and what its underlying logical structure is.

HCE is a subarea of Human Enhancement (HE) addressing interventions in human cognitive capabilities and processes, such as those conducted as part of medical research (restorative/therapeutic) as well as those aiming at enhancing or replacing given biological human faculties $^{2}$, including also the domain of moral enhancement ${ }^{3}$. Cognitive enhancement can alter the human personality and identity much more profoundly than does corporeal enhancement, and therefore it requires more urgently a proper philosophical and ethical analysis.

HE technologies and systems, when coupled with a human and her body, strongly elicit the feeling of intrus ('the intruder'), as discussed in Nancy's seminal paper 'L'Intrus't . The question of their acceptance is thus indeed of great philosophical importance, far overreaching ideological and biopolitical concerns. One of the key aspects of the acceptance of $\mathrm{HE}$ (individual, social, cultural) is naturalness, as can be seen e.g. from the work of Francis Fukuyama ${ }^{5}$, Ryuichi Ida ${ }^{6}$, or generally the whole HE overview book edited by Nick Bostrom and Julian Savulescu? The advocates of enhancement either assert that HE systems are natural, or they that they might be artificial but that it is itself natural (or at least is not unnatural) to extend/enhance human natural body/cognition by these

\footnotetext{
2 Bostrom \& Sandberg (2009), BMA (2007).

3 Savulescu \& Maslen (2014).

4 Nancy (2002).

5 Fukuyama (2003).

6 Ida (2009).

7 Bostrom \& Savulescu (2009).
} 
systems. The bio-conservatives claim basically the opposite ${ }^{8}$ Therefore, the pro- and anti-enhancement feud can be at least partially transformed into a discussion about naturalness (in its more general sense), or even about the 'nature of naturalness'. In other words: HE acceptance can be seen through the looking glass of naturalness.

Even though the concept of naturalness does not find its place very often in the current discussions within mainstream bioethics ${ }^{9}$, its persisting importance can be illustrated by the recent focused project, study, and report of the Nuffield Council on Bioethics ${ }^{10}$ that reviewed the usage of the terms natural, unnatural and nature in various discursive contexts including bioethics, commercial sector and public or parliamentary debates. However, even that study focuses only on one side of the whole problem: a textual analysis of how natural and unnatural are used discursively as placeholders for many different value-laden or value-neutral concepts and connotations. See, for example:

"Often when people describe something as natural or unnatural in the context of a debate about science, technology, or medicine they are using those terms to make claims about that thing being good or bad, or right or wrong." ${ }_{11}$

The Nuffield Council's study does not provide an analysis of whether something like naturalness really exists objectively, perhaps as a predicate that assigns a certain immutable quality to all phenomena (objects, processes) that are natural, much in the same way as for example red assigns a quality of redness to all the objects that are red. Moreover, rather than explaining what the logical structure of naturalness is, that study explores various ideological structures of naturalness in various biopolitical discourses, which is also very important, but for other purposes than those that I want to pursue here.

\footnotetext{
8 Moreno (2011), Kass (2004), McKibben (2004).

9 Smajdor (2015).

10 NCB (2015).

$11 \mathrm{NCB}$ (2015, p. 14).
} 
It is therefore the goal of the present article to supplement and extend studies such as that of the Nuffield Council report, with an analytical account of the concept of naturalness, which can perhaps help in understanding what is so specific about naturalness that makes it always so difficult to truly use it in a different way than just as a discursive placeholder. I will also try to make explicit distinction between artificial and unnatural, even though these two terms are apparently often used interchangeably ${ }^{12}$ because of their similar negative values and connotations in many discourses.

As the author, I am aware that I am trying to transdisciplinarily blend such different fields as phenomenologically motivated non-standard set theory, bioethics, analytic philosophy and even somewhat speculative metaphysics as a source of intuition. And I am also aware that this mixture can indeed be hazardous and can upset experts from literally all these fields due to various technical, methodological, and even conceptual issues. However, I also honestly feel that many traditional correct approaches are somewhat stuck in an inability to provide guidance in acute and pressing questions and problems of rapid technological development that can profoundly change the human (one of which is, e.g. the here discussed HCE). So this article has been prepared with motivation driven from the mission of Epstein's Transformative Humanities ${ }^{13}$, which can perhaps help constructively soften some of its rough edges.

\section{Building an Intuition}

Before I attempt to build a formal set-theoretical model of naturalness, I will explain the intuition behind this proposal of how 'natural' relates to 'artificial', how 'artificial' is different from 'unnatural' and how 'naturalness' differs from human naturalness.

\subsection{Human Naturalness}

I would like to bring to attention two concepts from ancient Greek philosophy: physis and logos. It is true that in their classical philosophical

12 NCB (2015).

13 Epstein (2012). 
usage they usually do not form mutual opposites, but I believe that contrasting them can be useful for our purposes.

Physis is a concept referring to all things that grow on their own, intrinsically; to things that are in and created by Nature. It was used by the Greek god Hermes when he pulled out a plant to show Odysseus its intrinsic way of growth. It is something that all the discursive usages of the words nature and naturalness (as analysed by the Nuffield Council Report) have in common: it is their conceptual core. However, we can intuitively feel that it is very difficult to truly grasp what physis really is. All the uses of nature and naturalness in all the contexts and pragmatic domains refer to it, but it is as if the substance of physis always slipped away. We will see in the next sections why this is so, but for now let us intuitively understand physis as the core of naturalness, as the intrinsic way of growth shown by Hermes.

Logos, on the contrary, means the whole complex and metaphorical concept of speech, meaning, human reason, rationality. Ever since the philosophy of Heraclitus, it has been used to denote the principle of order and knowledge. Just as physis is the core of all the natural things that grow by themselves without any human intervention, logos is the core of the logic behind all rational arguments that inherently pertain to the set of aspects delimiting the human from the rest of Nature.

The Nuffield Council Report shows how often in public, media and policymaking discourse the naturalness-related words are value-laden, and especially with positive values. From there, the public tends to resort to the naturalistic fallacy ${ }^{14}$. The concepts of physis and logos, on the other hand, should be value neutral, or better said, they connote such a diverse set of opposing values that I would call them rather value ambivalent. Physis connotes with raw untamed things, growth, procreation, reactivity, wilderness, warmth, dynamics, spontaneity, vortex, chaos, vagueness, mud, dust, rot, worms, turmoil, and also excessive growth (as in cancer). Logos connotes clarity, purity, intentionality, geometry, logic, cold, static, copying, algorithm, and also excessive loss (as in Alzheimer's disease).

We can intuitively construct a continuous spectrum representing the scale of the degree to which we judge a given object or process as pertai-

14 Smajdor (2015). 
ning to physis or to logos, having abstract pure physis on one extreme side of the spectrum and abstract pure logos on the opposite extreme side. The roots of an herb happily and undisturbedly growing through the dark of the soil would be very close to the physis end of the spectrum, while the roots of a polynomial function are just at the opposite end, very close to logos.

I then assert that we should put human at the middle of this spectrum. When we define 'human', we automatically delimit this concept from 'lesser' animals by an inherent interconnection with rational and abstract thinking, hence as a logos-creature, but at the same moment we stress the human's strong embedding in a 'natural' biological origin in order to delimit the human from all the artificial entities and interventions triggered by technological development (as often appearing in public discoursed analysed e.g. by Smajdor or Nuffield Council Report ${ }^{15}$, hence as a physis-creature. Metaphorically speaking, human is a being of the tension between physis and logos, a being producing and produced by this tension, a being that possesses about the same from both realms. Therefore, 'being as natural as human' means 'having the same ability to balance in the equilibrium between physis and logos'. So we would expect also HCE systems to respect this kind of human naturalness: neither dragging human beings too much towards logos nor towards physis.

Every thing, every object, has its share of the artificial and the natural. There is no purely natural object because the objectness itself is the first trace of artificialisation. Understanding a fragment of reality as an object is a matter of the logos and thus it gives the first blow to its pure naturalness. The tools of logos pull out pieces of inherently non-structured physis and construct shapes and objects from them. When Hermes showed the herb, drawing it from the ground to demonstrate its nature (its physis, the physis was already retreating. It was still somehow very strongly there, much more strongly than if Hermes had shown a plastic bag or a microchip, but no longer in its pure form because artificiality had already crept in: the herb 'being shown' is not the herb 'being natural' inseparably in its physis.

15 Smajdor (2015), NCB (2015). 
What Hermes did was something very typical for a human, or even delimiting for a human mind, thought, and intelligence. If an animal were to interact with an herb instead of a human, it would not show/ objectify/name the herb - it would simply transparently share with the herb their 'unspoiled' and non-conceptualised physis together. On the other hand, if it were a machine instead of a human, it would operate only with purely symbolical representations completely detached from the intrinsic substance of the herb, and the herb itself would be replaced by a single symbol, or a symbolic representation of its geometrical model, or a symbolic representation of its molecular structure, or something similar. In other words, logos dissolves physis, and the human is, in its nature, a steersman constantly oscillating around this unstable equilibrium where objects appear from the mud of physis before they disappear into the void of logos. We can also see this metaphor as a keen variation of Wiener's and Ashby's ${ }^{16}$ cybernetics. ${ }^{17}$

Human naturalness is thus something significantly different from naturalness seen merely as physis. Human naturalness is an indivisible and intrinsic combination of the natural and the artificial, continuously re-enacted by the process of life itself. Therefore, should there be any bioethical account of naturalness in HCE, it must be grounded in the aforementioned human naturalness, because otherwise if it again resorts only to the purely physis-based understanding of naturalness, we will not be able to prevent it from drowning in the naturalistic fallacy.

\subsection{Natural and Artificial Objects}

We can say that a major tool for such a steering between physis and logos is language. Language in general is a long bridge between physis and logos, with deixis and protolanguages close to the bank of physis, formal languages, mathematics, geometry, etc., close to the bank of logos, and natural language somewhere in between, where human minds operate.

When we use language to further analyse a freshly objectified (shown) object in more detail, we go step by step over this bridge and we start

16 Ashby (1957).

17 As Prof. Cyril Höschl, director of Czech National Institute of Mental Health, informally noted during one of his lectures: "Life is a process of sailing between Scylla of cancer and Charybdis of dementia." 
losing more and more of the object's naturalness. The object in itself stays the same but we receive more and more detached abstract concepts. Although such concepts are new objects transferable by means of language, they lose their connections to the inherent givenness of the original object.

For example, no human being can describe in words how the root of a herb (or a cloud, a bird's nest, a coral) exactly is. The moment closest to the root's naturalness is when we show it (deixis), and after that the more we say about it in an attempt to fully describe it, the more artificial a construct we get. At some point, the length of the description reaches beyond the limit of any human being and becomes manageable only by symbol processing machines, having no meaning for a human while being in this logos domain. For example, a 'sentence' with 10 million 'words' might be quite a good description of how the root is, but only as long as we interpret it as a 10-megapixel photograph of the root, forgetting everything about the language and humbly returning back to showing the root or at least its image, i.e. back to a much more physis-related deixis. The logos-based interpretation of those 10 million symbols (i.e. reading and understanding them one by one) has absolutely no meaning for us.

So what is the natural? The natural is that which defies being captured by language. Naturalness - or physis - is everywhere where we feel tension between what we wanted to capture by our words and what we really captured. The more the tension, the more naturalness we just encountered. The natural is something that we have to abstract away from in order to capture it by language.

In contrast, the artificial is imposed by language: the artificial is that whose essence is fully determined by language. The artificial is a language-implemented abstraction drawn from the soil of physis and attracted by the clarity of logos.

Let's imagine an old rustic wooden table. What is artificial about it? That which we can grasp with words: the shape and size of its geometrical idealisation, its weight, colour tone, purpose, or perhaps a description of the way it was made by a carpenter with an axe, a saw, and a jack plane. However, we cannot describe how exactly it looks, how it feels 
when being touched, the exact look of its texture and wood structure, its smell.

Now let's imagine a three-legged white round plastic garden table. How to grasp it with words? Just take its designer's drawings and the description of the technological aspects of its manufacture, and we have it right in front of us. We do not need to see and touch and feel this table to fully know how and what it really is. Hence, it is almost completely artificial. Yet even such an artificial thing has something natural about it: various scratches, defects, imperfections, shabbiness, but most importantly its inherent qualia potential that we exploit when we meet the table right here and now. All these aspects defy being captured by words, and therefore are natural.

It is important to mention in this place that terms such as 'natural variation' and 'natural sugars', or sentences such as 'hedgehogs are a part of the UK's natural wildlife' use natural in a different meaning than what we have discussed so far: they use natural in the most common and simple meaning, referring to those things that have not been subject to human intervention (which is a very exclusive meaning because it excludes all human activities from being natural) or originate in a source that was not created by humans. However, we can still get the question whether fully grown forests manually planted by humans hundreds of years ago are a part of 'natural wildlife'. Probably yes, but are they also natural? And this is the moment when we must get back to our definition of natural formulated in the paragraphs above.

\subsection{The Artificial and the Unnatural}

The term artificial should be perceived as relatively value neutral, whereas unnatural clearly carries a heavy load of negative values. Both are, however, used as the opposite of natural:

"Our work identified an asymmetry between use of the terms natural and unnatural. It found that, proportionately, there is a contrast between the regularity with which value is invoked by use of the term natural and the term unnatu- 
ral [...] Within the sources reviewed, the term natural was used much more commonly than the term unnatural and was typically used in a value-neutral way. In contrast, when the term unnatural was used, it was often used to suggest something is wrong or bad."18

From the textual examples that the Nuffield Council's report presents (e.g. "The instinctive desire within many of us not to consume something that is unnatural - the fear of so-called Frankenfoods.", or "I was also unhappy with the idea of having something as unnatural as a silicone implant in my body.") it is apparent that almost always when the term unnatural is used, it means something not only wrong or bad, but also repulsive or abhorrent.

It seems that in many discourses, especially public and in the media, the term artificial is used in the same sense, i.e. losing its value-neutrality, e.g. in "Most of the 600 people working at Thanet Earth appear to believe passionately in what they do, and angrily reject the charge that they are somehow perverting nature or creating something artificial." However, I will put this usage of artificial aside here because these cases simply look like common mistakes in word selection resulting from ignorance or semantic carelessness, because 'creating something artificial' is actually very natural for humans: it is an inherent part of human naturalness.

What I suggest here is to understand unnatural strictly as the opposite of human naturalness, not as the opposite of natural in the sense of physis. This will fit perfectly most of the discursive usages of unnatural. Artificial then can be the opposite of natural in the sense of physis.

'Frankenfood' is thus unnatural because it repulses human naturalness, no matter whether it is artificial or coming from physis. Analogically, bread or sushi or traditional English Christmas pudding are quite artificial in the way they are made, yet they are perfectly natural in the sense of human naturalness. And a human being having two heads (one of them perhaps necrotic) and three arms is very frightening, repulsive, and unnatural, even though it could quite possibly happen in an entirely natural way through the blind powers of physis.

$18 \operatorname{NCB}$ (2015, p. 19). 


\section{A Formal Model of Naturalness}

The presented reflections show that in discussions about HCE, it is not necessary to give up on the concept of naturalness as being too inclusive (everything that appears in the natural world, including all the human artifacts, is natural), or too exclusive (only those things that have not been subject to human intervention are natural), or just a conversational placeholder for various value-laden judgements (as analysed by Nuffield Council Report $\left.{ }^{19}\right)$. Naturalness is not an empty concept - it is just a concept with a different internal structure than we are generally used to, and it is much more difficult to represent this structure and operate with it. So in this section, I will try to outline a way to formally grasp and anchor naturalness - both in the sense of physis and in the sense of human naturalness.

The question now is how the internal structure of naturalness is different from what we would have naively expected. I will analytically tackle this problem by using a set-theoretical approach for modelling the underlying structure of naturalness. However, the standard axiomatic set theory (Zermelo-Fraenkel set theory in the classical Cantorian universe of sets) does not offer suitable tools able to properly represent the phenomenal aspects of naturalness, into which we have intuitively gotten insight in the previous section. The necessary (yet standardly missing) formal tools can be summarised in a simplified way as infinitesimal (infinitely small, beyond any measurable size) elements or vague elements - and the standard set theory has none of them.

A well-known nonstandard set theory is Nelson's internal set theory ${ }^{20}$ which builds on the non-standard analysis introduced by Robinson in the 1960 's ${ }^{21}$. The problem with Nelson's and Robinson's approaches is that they, while being very well elaborated and axiomatised and while introducing infinitesimals, are built without any phenomenal intuition that would help us link them easily with the phenomenally perceived internal structure of naturalness (or any other concept used in natural language). However, there is another nonstandard set theory, introduced

19 NCB (2015).

20 Nelson (1977).

21 Robinson (1966). 
by Vopenka, usually called Alternative Set Theory (AST) or the Theory of Semisets. It is very similar to Nelson's system in terms of its formal mathematical aspects (including similar mathematical advantages but also various technical difficulties), but unlike Nelson, Vopenka has built the whole system of AST on very profound phenomenal intuitions, making it much more accessible outside the scope of pure mathematics.

Unfortunately, Vopenka's AST faces another problem: for various historical and political reasons, the bulk of Vopenka's work has been published mostly in Czech, without a proper English translation (Vopenka was persecuted by the communist regime in Czechoslovakia, banning him from publishing internationally). Only an early version of AST was published, in 1979, in an English monograph ${ }^{22}$, i.e. in the period of high interest in nonstandard analysis among mathematicians, but all the subsequent developments were published mostly in Czech, Slovak or Russian $^{23}$, after the mathematical mainstream had taken a different way. This makes it much harder now to build and publish anything on top of Vopenka's AST framework because he has been internationally well known only in a very specialised group of theoretical mathematicians (e.g. Holmes ${ }^{24}$, or Kanamori ${ }^{25}$ elaborating Vopenka's earlier works on large cardinals and Vopenka's principle). Only recently, shortly before he passed away in the spring of 2015, did Vopenka finish the final draft of an English monograph comprising a fully rewritten and updated version of AST. This had been in its first version available as a preprint ${ }^{26}$, and now the final edited version is pending publication ${ }^{27}$. So I will try to very briefly introduce, for the non-mathematician reader of the present article, some of the most important principles of Vopenka's AST (even though this makes the article significantly longer). Then I will use these principles to model the concept of naturalness.

22 Vopěnka (1979).

23 Vopěnka (1989, 1996, 2001, 2014, 2015).

24 Holmes (2012).

25 Kanamori (2009).

26 Vopěnka (2012).

27 Vopěnka (2019). 


\subsection{Horizon, Natural Infinity, and Semisets}

The key concepts in AST are built around what Vopenka calls natural infinity. Unlike actual or potential infinity, natural infinity represents such an infinite quantity that can be found in the real natural world and can be phenomenally processed by a human-like observer. Classical Greek geometry operated with potential infinity where a geometric line is always finite but can be potentially prolonged anytime by any finite length, hence being infinite in potentiality. This infinite prolongation was given to the powers of Greek gods such as Zeus, so it got out of reach by any human; but not even Zeus was able to oversee the whole line in its actual infinity after all the (infinite number of) potential prolongations had been expanded. Such an omnipotent sight, encompassing all the actualised infinities at once, has been given to the Christian God, and in the form of the actual infinity has been firmly installed in the classical Cantorian set theory, where all the possible crystal-clear finite and infinite sets and all their powersets ${ }^{28}$ exist at once. It is clear that most of the abstract entities existing in Cantor's set universe do not have any counterparts in the whole physical universe, let alone in its phenomenally conceivable part.

Natural infinity, on the contrary, was defined by Vopenka with a strong link to the concept of horizon:
"Every look ${ }^{29}$ we cast, no matter in what direction, is limited. Either there is a firm boundary which disrupts (or deflects) it sharply, or it is limited by a horizon in whose direction clar- ity decreases and sharpness blunts." 30

Thus, a naturally infinite abstract structure would be the class of natural numbers that number the steps needed for an observer (who casts the look) to take her directly to the horizon. In the ordering of those natural numbers, there is no such number about which we could say that it is the

\section{Powerset is the set of all subsets of the given set.}

29 A look here does not refer merely to a look by sight (with physical eyes); we understand it in the broad sense of regarding something that has been encountered. [The footnote is a part of the original quotation].

30 Vopěnka (2019, p. 62). 
last number reaching the horizon, i.e. if $n$ belongs to the class, then $n+1$ belongs to it too. In this sense, the class is infinite. However, we know that there is a finite (perhaps very big) number $N$ about which we know that if we make that many steps, we will definitely get past the horizon. This means that naturally infinite classes are subclasses of large classical finite sets. These subclasses are called semisets and they are a crucial structure of AST that, apart from being naturally infinite, also model the phenomenal concept of vagueness.

We can see here that the horizon is a rather general epistemological concept, but it is also very often helpful, for gaining an initial intuition, to illustrate it on plain visual examples, such as a long straight railway track with railway sleepers marking the steps to the horizon and beyond.

The fact that we are constructing a set theory where infinite classes are subclasses of finite sets might seem very counterintuitive at first. This situation is, however, quite similar to the hard first step that had to be done on the way from Euclidean geometry to non-Euclidean geometries: to concede that two parallel lines can have a point of intersection.

There are many intuitive examples of real-life naturally infinite semisets (just as there are intuitive examples/models of non-Euclidean geometry, e.g. meridians on the globe that are all parallel and still have two intersections at the poles). The whole class of sorites paradoxes is one of them: a naturally infinite semiset represents the class of sand grains that have to be removed from a sand heap before it is not a heap anymore (or it can be the 'bald man paradox' if we want to speak about hair instead of sand). The same actually can hold for the extensions of most natural language predicates, such as 'tall', 'old', 'pretty', 'smart', 'green', etc. In the case of colour gradients (e.g. continuous red-to-green transitions), semisets are the classes of all the adjacent colour tints that we perceive as a single colour, e.g. 'green'. We know that if a particular given tint is green, its immediate neighbour will also be green, but if we skip over enough tints we will reach something that we quite clearly identify as red.

Semisets also represent the classes of all those colour tints that are mutually indistinguishable. However, as I will show later, the internal structure of these indistinguishability semisets is inherently different 
from the structure of semisets that represent the aforementioned predicates. And it is exactly this structural difference that pertains to naturalness as a discursive placeholder analysed by the Nuffield Council Report (its structure is similar to the structure of predicates like 'green' or 'tall') versus naturalness as physis (its structure is similar to the structure of indistinguishability).

Years ago, Vopenka gave another good example ${ }^{31}$ (originally meant as rather humorous and relaxed) of a natural infinity, which now has a strong link to the topic of HCE: let's imagine a set of individuals starting with some prehistorical primate (let's call her 'the monkey' for the sake of simplicity, even though this will quite likely upset many biologists, and not just them), then going through all the direct descendants of the monkey up to some human actually living these days (for example, me). This set is clearly a finite set. A naturally infinite semiset is a subclass of this set that corresponds to all the individuals from that direct hereditary line who are monkeys, because we know that if an individual is a monkey, her direct offspring is also a monkey; but we also know that there are some individuals further in the same hereditary line who definitely are not monkeys anymore.

This very well illustrates the close connection between vagueness (as inherently present in the natural language predicates) and infinitesimals. The aforementioned monkey-human sequence can actually be also understood in such a way that a direct offspring of each monkey individual is infinitesimally less monkey than this individual, and vice versa, a parent of each human individual is infinitesimally less human than this individual. The infinitesimality here means that the change is so small that it is beyond any measurable means within a given system.

When we speak about the set-theoretical universe itself, the infinitesimal entities are smaller than any real number (where a real number is the measure), which is exactly the case in the systems of Robinson, Nelson, and also Vopenka. But outside of the strictly formal set-theoretical apparatus, when applied to the real world, we can see that infinitesimal features can be found even in the objects normally perceivable by

31 This example is from (Vopěnka 2001) but even there Vopenka stated that he had originally presented it 'long time ago'. 
the bodily senses - just like the sand grain in the case of the heap of sand is infinitesimal with respect to the heap. Infinitesimality is an epistemological aspect of the look being cast at a fragment of reality. And this is where the phenomenological intuition behind Vopenka's formal system is very useful. Moreover, it immediately draws our attention to the fact that even certain HCE interventions may exhibit exactly this kind of infinitesimality with respect to human naturalness.

\subsection{Two Internal Structures of Semisets}

It is unavoidable to use at least some very basic mathematical notation in this section, but I will limit it to the minimum (comprehensible to anyone with some basic high-school knowledge of mathematics) and also the explanation will be illustrative rather than axiomatic. Note on terminology: the term set in AST is used strictly for a finite structure (the same as the finite sets in standard set theory), the term semiset is used for a naturally infinite structure (this is specific to AST; it is not present in standard set theory), and the term class can be used both for sets and semisets, i.e. all sets are also classes, but not all classes are sets because some of them can be semisets. This also means that a semiset is a naturally infinite subclass of a finite set.

We start with a less formal and more intuitive definition of function. A function $F$ is a structure that takes an input value $x$ and on the basis of a fixed mapping returns exactly one $y$ for this given $x$, formally written as $F(x)=y$. Both $x$ and $y$ can generally be any abstract entity modelled within the set universe, such as numbers (natural or real), sets, sets of sets, sets of numbers, etc. However, in this article, it will be enough for us to suppose that our functions take only numbers and return only sets of numbers. For example, consider the function that, for the input number 4 , returns the set of three numbers $2,6,9$, i.e. in the formal notation $F(4)=\{2,6,9\}$, and for the input number 5 it returns the set $\{2,6,8$, $10\}$, i.e. $F(5)=\{2,6,8,10\}$. And by coincidence, when our function takes the number 6 , it returns the same output as for the number 4 , i.e. $F(6)$ $=F(4)=\{2,6,9\}$. Our function accepts only these three input numbers, it is not defined for any other input number. An important point is that 
a function itself is a set within the set universe: it is a set containing ordered couples $\langle y, x\rangle$.

The set of all those $x$ for which the function $F$ is defined is called its domain. The notation for the domain of $F$ is $\operatorname{dom}(F)$. In our case, $\operatorname{dom}(F)$ $=\{4,5,6\}$. The set of all possible $y$ that the given function can return is called its range, and its notation is $\operatorname{rng}(F)$. In our case, $\operatorname{rng}(F)=\{\{2,6$, $9\},\{2,6,8,10\}\}$. Note that the range of this $F$ is a set of two sets, one containing three numbers, the other containing four numbers.

Every reader is probably familiar with the operations of set union (denoted $U$ ) and set intersection (denoted $\cap$ ). So if we have a set $A$ that contains any number of sets as its elements, then the set $U A$ is constructed as the union of all the sets that $A$ contains. Analogously, $\cap A$ is constructed as the intersection of all the sets that $A$ contains. In case of our example $F$, we have $\operatorname{Urng}(F)=\{2,6,8,9,10\}$ and $\cap r n g(F)=\{2,6\}$. We can see that the sets constructed by $U$ can be 'growing' if we add more sets to $A$, whereas the sets constructed by $\cap$ can be only 'shrinking'.

The segment of the natural numbers determined by $n$ is the set of natural numbers $\{0,1,2, \ldots n-1\}$, i.e. the set of $n$ consecutive natural numbers starting with o. On this basis, AST introduces a new structure called a horizon segment, which is such a segment $H$ where two conditions must be met: 1 ) in the natural number ordering, $H$ has no last element $m$, i.e. it is infinite; 2) any function $F$ defined on $H$ (i.e. $\operatorname{dom}(F)=H$ ) can be prolonged to a finite set. These two conditions, their justification and their consequences are discussed by Vopenka in detail ${ }^{22}$ but these discussions are far beyond the scope of this article. For us it is important to know that a horizon segment $H$ is a basic semiset and a basic set-theoretical model of natural infinity.

Now we are getting close to grasping two important internal structures of semisets. Let $X$ be a class, either a set or a semiset - it does not have to be a segment, it can simply be any finite set or any naturally infinite semiset. And let $H$ be a horizon segment.

If it is possible to find a function $F$ defined on $H$ (i.e. $\operatorname{dom}(F)=H$ ) such that $X=\operatorname{Urng}(F)$, we call $X$ a $\sigma$-class. And if it is possible to find a func- 
tion $F$ defined on $H$ such that $X=\cap r n g(F)$, we call $X$ a $\pi$-class. From the meaning of the operators used in them, we can say that $\sigma$-classes have the 'growing' quality in them while $\pi$-classes have the 'shrinking' quality, just as, a couple of paragraphs above, we discussed in the example with the simple finite function, only now the constructing function $F$ (i.e. the function that 'constructs' $X$ ) is defined on a naturally infinite semiset, not on a finite set -- which makes it far more interesting.

Vopenka has constructed a lot of formal propositions and proofs about $\sigma$ - and $\pi$-classes and has built a rich theoretical apparatus around them ${ }^{33}$. At this moment, we will focus only on two of those propositions, which assert the following (rather simplified here):

1. A class $X$ is both a $\sigma$ - and $\pi$-class at the same time if and only if $\mathrm{X}$ is a set. This means that if $\mathrm{X}$ is a set (i.e. a finite structure, just as in standard set theory), we can find both ways of constructing it from different functions defined on a horizon segment $\mathrm{H}$ : the 'growing' way $U$ as well as the 'shrinking' way $\cap$. However, if $\mathrm{X}$ is a semiset (i.e. a naturally infinite structure), it can only be either a $\sigma$-class, or a $\pi$-class, not both at once. It means that there are two different kinds of semisets: those that we can construct only in the 'growing' way $U$, and those that we can construct only in the 'shrinking' way $\cap$ - based on their internal structure.

2. If $X$ is a $\sigma$-class and $w$ is a set, then $w-X$, i.e. the complement of $X$ with respect to $w$, is a $\pi$-class. And the other way around, if $X$ is a $\pi$-class, then $w-X$ is a $\sigma$-class.

As we have already mentioned, predicates within natural language are due to their inherent vagueness and lack of absolutely sharp boundaries - very well modelled by semisets. Many of these predicates have the structure of a $\sigma$-class, more specifically, those predicates standing for phenomena that Vopenka calls primarily evident phenomena:

33 Vopěnka (1989, 2001, 2015, 2019). 
"A primarily evident phenomenon is a phenomenon which we are able to evidence, that is, we are able to see it and know that we are seeing it as soon as it can be evidenced, that is, as soon as it has appeared to us.

For example, if we look at this page of this book, we will probably agree that it is not red. In the sensorily perceptible world [...], interpreted in the usual way as a community of objects, we interpret non-redness as a unary attendant phenomenon. [...] The phenomenon we are discussing is before our eyes on this page. But to be able to evidence it, we must first know redness from somewhere: in other words, we must have evidenced redness at an earlier date. Non-redness is thus not a primarily evident phenomenon. By contrast, redness is a primarily evident phenomenon because even if we had not come across this phenomenon before, we would notice the red colour as soon as we first saw it." ${ }_{34}$

It is exactly this distinction between primarily evident and non-primarily evident phenomena that can be captured as a distinction between $\sigma$-classes and $\pi$-classes, where $\sigma$-classes are formal models of primarily evident phenomena and $\pi$-classes are formal models of nonprimarily evident phenomena. The predicate 'red' is a $\sigma$-class which can be formally constructed for example by a function $F_{r e d}$ that returns a set of red objects (or rather their abstract placeholders, e.g. numbers) for each time point when somebody (e.g. me, or the whole of mankind, it does not matter in this example) sees some objects, and the class of these time points is a horizon segment $H_{\text {time }}$ on which $F$ is defined.

In case of the complementary predicate 'non-red', one might think that we can formally construct it the same way as 'red', i.e. analogously by applying the union operator $U$ over sets of non-red objects given by the function $F_{\text {nonred }}$ defined on the horizon segment $H_{\text {time }}$ (and the standard set theory that does not support semisets would actually lead us to this conclusion). However, the aforementioned proposition (2) tells 
us that this is not possible. The extension of 'red' clearly is not a set but a semiset, so following from (1), 'red' is only a $\sigma$-class, not a $\pi$-class at the same time, hence following from (2), 'non-red' as the complement of 'red' is only a $\pi$-class, not a $\sigma$-class at the same time, and therefore there is no way to find a function that would construct 'non-red' by the union operator $U$ in the 'growing' way. The only way how to construct 'nonred' is by the 'shrinking' intersection operator $\cap$. And this is indeed supported by our intuition: from observing only and only 'non-red', there is absolutely no way how to understand (and phenomenally process) what 'red' is - we even would not know that we observe 'non-red'.

This way of constructing the $\pi$-class 'non-red' places very different demands (in terms of their semantics) on what entities the constructing function $F_{\text {nonred }}$ can return. While the constructing function $F_{\text {red }}$ for the $\sigma$-class 'red' is doing fine by returning sets of red objects (their abstract placeholders) because the final extension of the predicate 'red' is then the union $U$ of all these sets of objects, the constructing function $F_{\text {nonred }}$ for the $\pi$-class 'non-red' cannot analogously return plain observed nonred objects because the operator of intersection applied to them would soon produce the empty set $\emptyset$, as no non-red object would appear in absolutely all (naturally infinite number of) sets of non-red object observations given by $F_{\text {nonred }}$ on $H_{\text {time }}$. Instead, the function $F_{\text {nonred }}$ must return, for example, very big finite sets of attributes (i.e. actually other predicates) of the observed non-red objects, not the objects themselves, because after applying $\cap$ to all these naturally infinite number of sets of attributes, we would get the class of attributes that all the non-red objects share: the $\pi$-class of the 'essence' of 'non-red'.

This is a very important difference between the internal structures of the primarily evident phenomena such as 'red' and non-primarily evident phenomena such as 'non-red'. From the difference in demands placed on the constructing functions of primarily and non-primarily evident phenomena, we can somewhat eloquently conclude that the underlying structure of primarily evident phenomena (and their respective predicates) is the aggregate of what they are, whereas for non-primarily phenomena, it is the essence of how they are. 
It is not easy at first to intuitively fully comprehend the somewhat strange structure of a $\pi$-class. So for further illustration, let's imagine the situation that I have a piece of paper from which I start to tear off little pieces one by one so that the remaining piece of paper is smaller and smaller after each step. I can do this until the remaining piece of paper falls behind the horizon of distinguishability of my bodily senses (which determine the horizon of my look at these objects), leaving an infinitesimally small (now invisible for me) 'trace on the horizon' - an infinitesimally small geometric point. However, this geometric point actually still consists of a huge number of molecules, as if 'hidden' behind this infinitesimal geometric point, while the geometric point is their projection on the horizon (hence the 'trace' - as if the molecules disappeared beyond the horizon of my bodily senses, leaving only this trace in the form of an infinitesimally small geometric point being able to form the continuum with nearby similar traces/points). And the class that these remaining molecules form is a $\pi$-class. The class of the steps of tearing off the pieces of paper until this situation happens is a $\sigma$-class.

This brings us to another important part of Vopenka's AST, which I will mention here only very briefly: a set-theoretical framework for topology and continuum analysis based on naturally infinite semisets. To put the matter in a very simplified way, this framework gives us tools, for example, for the description and analysis of how continuous shapes of objects are created from the underlying structures of discrete entities, e.g. how the continuous shape of a piece of paper appears on top of the huge class of its discrete molecules. It is based on a formal definition of the relation of indistinguishability, which is a $\pi$-class defined as a class of underlying discrete entities that are mutually indistinguishable, e.g. the class of the paper's molecules that behind the horizon merge into a single geometrical point of the paper's continuous shape, or a class of mutually indistinguishable pixels on a high-resolution screen. This class is a $\pi$-class because it is defined as the complement of a relation of distinguishability, which is a $\sigma$-class of a primarily evident phenomenon of distinguishability of two objects. The relation of distinguishability contains, e.g. all pairs of the paper's molecules that I can mutually distinguish by cutting the paper into two pieces so that one molecule stays in 
one piece of the paper and the other molecule stays in the other piece of the paper.

This is the reason why also all the colour tints that I cannot mutually distinguish constitute a $\pi$-class, whereas all the mutually distinguishable colour tints create a $\sigma$-class. And all the colour tints that I perceive as green create another $\sigma$-class.

\subsection{Naturalness as Semiset}

Having the intuition about naturalness together with the formal models of primarily and non-primarily evident phenomena, we can now link these two. We will do this here with the dichotomy natural-artificial, but the very same steps can also be taken for the dichotomy natural-unnatural.

From what we have discussed in Section 2.2, we can now see that artificial is the primarily evident phenomenon represented by a $\sigma$-class constructed from all objects (both physical as well as abstract, such as geometrical shape, quantity, etc.) that we can grasp by language and thus account for them as products of human logos-driven activity, hence as artificial. Therefore, the predicate 'artificial' says what 'artificial' is. Apparently, this $\sigma$-class is naturally infinite, i.e. it is a semiset, not a set, and therefore it is not a $\pi$-class.

In contrast, natural as the complement of artificial must be a naturally infinite $\pi$-class. It is constructed from all the features that we fail to grasp by language while constructing an understanding of the objects of the sensorily perceptible world. The constructing function of this $\pi$-class 'collapses' a naturally infinite number of these features into a 'core' that is common to all the instances of naturalness - saying how 'natural' is. This structure is also naturally infinite but in a very different way than the naturally infinite class of the extension of the predicate 'artificial'. Just like in the example of 'red' and 'non-red' in the previous section, by observing only natural we would not be able see what artificial is, and we even would not know that it is natural what we are observing.

The quality artificial is, for example, that of a class of all the objects that somebody can see in her life. The quality natural, in contrast, is that 
of a class of all the molecules of my table that I cannot distinguish one from another because they are all 'behind' one infinitesimal point that contributes to formation of the perceived topological continuum of my table.

Naturalness has a structure similar to that of a geometric point in Vopenka's sense. It is also similar to the structure of now in Vopenka's phenomenologically inspired model of time and the temporal continuum: ${ }^{35}$ on the temporal axis underlaid by a huge number of very dense yet still discrete atomic time events, the past is a $\sigma$-class of all the time events that have already happened, the future is a $\sigma$-class of all the time events that will happen, and between these two $\sigma$-classes is a $\pi$-class of time events belonging to now. This now also has a structure similar to a geometric point, and it can be 'wrapped' or 'embedded' into a larger $\sigma$-class of presence. However, due to its $\sigma$-class nature, the presence class of the time events that I perceive as presently happening cannot be disjoint from the past and future classes. We can see that artificial (or unnatural) is metaphorically (and mathematically) similar to past (or future), while natural is similar to now.

We can also see that the 'nature' of naturalness is far less intuitively imaginable and visualisable than the 'nature' of artificiality. This is probably the reason why most of the discussions about what natural is treat it as a discursive placeholder with a $\sigma$-class structure typical for the easier-to-comprehend predicates of primarily evident phenomena (similar to the aforementioned structural difference between now and presence - with natural as a discursive placeholder being analogous to presence). This can lead to a textual analysis of the discursive usage of various $\sigma$-class predicates commonly labeled by the word 'natural' ${ }^{36}$, but it usually does not lead to a deeper understanding of what naturalness is -- or rather of how naturalness is, because we already know we should not ask what naturalness is in terms of extension of this predicate. So when making some decisions (perhaps ethically motivated) about naturalness, we must consistently take into account that we cannot get the answer to what natural is; instead we must pose the question as how

35 Vopěnka (2001), Havel (2016).

36 NCB (2015). 
natural is, and possibly whether we interfere by our actions with this how or not.

We can also recall again the example with the wooden and plastic tables from Section 2.2 and model this situation with semisets. This means that now we are not modelling what naturalness is in general. Instead, we are trying to model a particular manifestation of artificial and natural in a given object, i.e. the structure of these predicates as they appear in the particular phenomenon that we cast our look upon.

Let $H_{\text {inst }}$ be a horizon segment of instances when we are able to assert something about the observed object (e.g. the table). How $H_{\text {inst }}$ exactly looks like is very much inherent to the particular look that is being cast but in all cases it must be something compatible with the spatio-temporal givenness of a human being beca use it is exactly this givenness that we relate natural and artificial to. We know that if we can assert a proposition, we will be able to assert one more, but we also know that we will never assert billion propositions. ${ }^{37}$ Then we can conceive a function $F_{\text {desc }}$ defined on $H_{\text {inst }}$ by which we are describing the observed object. For each instance from $H_{\text {inst }}, F_{\text {desc }}$ returns a set of propositions being described about the object. The class $\operatorname{Urng}\left(F_{\text {desc }}\right)$ is apparently the $\sigma$-class of all that 'can be grasped by language' (namely, the language pertaining to the look being cast), hence the class modelling the object's artificiality.

Let $w$ be a theoretically conceivable set of all possible propositions about the object made in all conceivable languages within all conceivable looks being cast at the object (not only the looks cast from a human's givenness). This is a bit problematic if we do not want to resort to the concept of an omnipotent God in whose mind these propositions are. However, we can for example imagine that there is a list of the actual states, positions, processes and configurations of all the molecules and other structural entities which the observed object is made of (or we can go to the atomic level, it is not that relevant for the argument here), including their causal connections to some higher level phenomena. Such a list might potentially be achievable one day as a result of scientific dis-

37 Perhaps the aforementioned Zeus can assert a billion propositions, but this only means that his view of naturalness will be somewhat different from a human's, because he casts different looks. The only speciality would be with the Christian God: He can assert the actually infinite number of propositions, thus for Him nothing is natural and all is artificial. But after all, this might not be eventually so surprising. 
covery but it will never be accessible in its wholeness to a human mind. And we can imagine this list to be one of many subsets of $w$.

The class $w-\operatorname{Urng}\left(F_{\text {desc }}\right)$ is apparently a $\pi$-class and it is exactly this class that models the naturalness of the observed object, i.e. all that is natural of this object. This class is extremely huge, yet still has the quality of a geometric point, as we have discussed above. All that is in this class is as if 'sunk' beyond the horizon on which it projects its trace, just as the pixels on a high-resolution screen are 'sunken' beyond the horizon of indistinguishability, projecting a continuous shape on the screen as their trace. It is not those propositions in $w$ that are natural - we do not see them anyway. What is natural is their trace $w-U r n g\left(F_{\text {desc }}\right)$. All that is natural in the given object is created by those entities from the internal structure of the object that are beyond the horizon of our look cast at the object - for example the $\pi$-class image of the mutual relations of billions and billions of molecules forming the shape of the wooden table. We know they are there but it is simply beyond the horizon of any language to describe how exactly they all are.

\section{Conclusion}

Getting back to our example with Hermes and his herb's roots: if we took a 10-megapixel photograph of it and watched it on a screen, a lot of things would be artificial - i.e. those things that we could say about it, having the structure of a $\sigma$-class. However, something would still remain natural: the exact root's shape that we see on the screen as the trace of the underlying pixels. The pixels themselves are indeed fully artificial (just as all the propositions in the set $w$ ) but we do not see them, we see only their trace in the form of a $\pi$-class. We may know (perhaps from the process of scientific discovery, or from the knowledge of how a computer screen works) that they are somewhere behind the horizon in the underlying structure of the shape that we see, but the only way to get to them, see them and distinguish them is to change the look that we cast at the object - looking at the screen from such a close distance (or even perhaps with a magnifying glass) so that we see the individual pixels - but losing the identity of the root itself, making it obsolete to ask about its naturalness. 
What we have just described in the previous sections is actually the same principle we can observe in emergent phenomena ${ }^{38}$. For example, within the emergentist paradigm of Artificial Intelligence, cognitive processes (or 'mental' phenomena) emerge on large complexes of locally quite simple units, such as in neural networks. Cognitive processes are $\pi$-class projections of the processes in neural networks running behind the horizon of our look cast at the systems to which we ascribe cognition. Neural networks are, metaphorically, like the pixels that we know are down there, yet we do not see them, only their images or projections on the 'screen' of the horizon pertaining to the look that we cast. And in the same way, the shape, colour and texture of the table are emergent phenomena over the molecular structures and processes within the table. If we look closer, the emergence disappears, but so does the shape; we can see the molecules, but we do not see neither the table, nor its shape and colour anymore.

What emergence needs (as I also argue elsewhere ${ }^{39}$ ) is a naturally infinite semiset $\sigma$-class, such as the one constructed by $F_{\text {dese }}$, and its complementary $\pi$-class; and the emergent phenomenon that we then observe is the $\pi$-class constructed by what is behind the horizon. However, this leads us to the conclusion that what we see as the emergent phenomena has the same structure as what we see as the natural - i.e. naturalness and emergence have the same structure. In other words, we can say that what is emergent that is also natural: the emergence is the way how the naturalness (in the physis sense, not human naturalness) is manifested in the objects that we observe. Emergence is also naturalness that 'creeps back' into artificially created systems. We may create a perfectly artificial neural network, but it is its emergent cognitive level where the naturalness gets back. I am not saying that naturalness equals emergence because the presented arguments are too weak to plausibly support the assertion that whatever is natural that is also emergent. However, I personally dare to propose so and open it for further discussion.

For HCE systems, technologies and interventions, we can propose the same conclusion in terms of their naturalness too. An HCE system is as natural as it is emergent. This is indeed a completely value neutral

38 Havel (2000), Silberstein (2001).

39 Romportl (2016). 
understanding of the natural. It will not help any ideological dispute between proponents and opponents of the particular system, nor will it say whether the system is good or bad.

For instance, if a dose of selective serotonin reuptake inhibitors (SSRI, a type of antidepressants) results in a moral enhancement of a subject so that she is more fair-minded and willing to cooperate ${ }^{40}$, then this very high cognitive and social phenomenon is clearly the emergent phenomenon over the vast network of brain causal interactions triggered by the SSRI, and as such, it is natural (just like remission of severe depression symptoms is natural in a depressive patient after the SSRI treatment). Similarly, the general sociocultural acceptance of coffee drinking as a stimulant is also an emergent phenomenon over the vast network of social and cultural interactions; and so if the same happens one day to SSRI usage for increasing fair-mindedness, then the overall society-wide increased fair-mindedness will also be natural.

It seems that the only naturalness-relevant criterion for bioethical considerations is the dichotomy unnaturalness versus human naturalness - and not artificiality versus naturalness. We can either postulate that some HCE intervention or system is unnatural (hence unacceptable), or we can design a logical argument why it is unnatural (based, e.g., on religious or ethical argumentation). In both these cases, the unnaturalness will be created artificially, by language, in front of the horizon. However, the unnaturalness (especially as a collectively perceived repulsion) can also emerge over an incredibly large structure of many individual emotional attitudes interacting mutually within a complex sociocultural discourse, in which case we get the natural unnaturalness.

Therefore, further bioethical debate within HCE should elaborate this complex non-linear functioning of how the inherent artificiality and naturalness of HCE systems (as determined by emergence within those systems) interact and influence the artificiality and naturalness of the meta-level unnaturalness and human naturalness (as determined by emergence within the meta-level sociocultural systems absorbing, judging and interacting with those HCE systems). In all other contexts, the concepts of artificial and natural should be left completely value neutral, which is, I believe, good for them.

40 Tse \& Bond (2002). 


\section{References}

Ashby, W. R. (1957): An Introduction to Cybernetics. Chapman \& Hall, London.

BMA (2007): Boosting your brainpower: ethical aspects of cognitive enhancements. Discussion paper, British Medical Association, London.

Bostrom, N. \& Sandberg A. (2009): "Cognitive enhancement: Methods, ethics, regulatory challenges." Science and Engineering Ethics 15 (3): 311-341.

Bostrom, N. \& Savulescu, J., eds. (2009): Human Enhancement. Oxford University Press, New York.

Epstein, M. (2012): Transformative Humanities: A Manifesto. Bloomsbury Academic, London.

Fukuyama, F. (2003): Our Posthuman Future: Consequences of the Biotechnology Revolution. Picador, New York.

Havel, I. M. (2001): "Causal domains and emergent rationality."

In Rationality and Irrationality: Proceedings of the 23rd International Wittgenstein Symposium, 20oo, Kirchberg, Austria, eds. B. Broggard \& B. Smith, öbv \& hpt Verlagsgesellschaft, Vienna, 2001, pp. 129-150.

Havel, I. M. (2016): "Model prožívaného času podle Petra Vopěnky." (English resume: "The Model of Experienced Time according to Petr Vopěnka”) Filosofický časopis / Philosophical Journal 64 (4): $539-560$.

Holmes, R. M. (2006): “Alternative axiomatic set theories.” In Stanford Encyclopedia of Philosophy [online]. 30. 5. 2006, substantive revision 12. 8. 2017 [cit. 3. 5 2019]. Available at: https://plato. stanford.edu/entries/settheory-alternative/.

Ida, R. (2009): "Should We Improve Human Nature? An Interrogation from an Asian Perspective." In Human Enhancement, eds. N. Bostrom \& J. Savulescu, Oxford University Press, New York, 2009, pp. 59-70.

Kanamori, A. (2009): The Higher Infinite: Large Cardinals in Set Theory from Their Beginnings. Springer. 
Kass, L. (2004): Life, Liberty and the Defense of Dignity: The

Challenge for Bioethics. Encounter Books, New York.

McKibben, B. (2004): Enough: Staying Human in an Engineered Age. St. Martin's Griffin, New York.

Moreno, J. D. (2011): The Body Politic: The Battle Over Science in America. Bellevue Literary Press, New York.

Nancy, J.-L. (2002): “L’intrus.” Translated by S. Hanson. CR: The New Centennial Review 2 (3): 1-14.

NCB (2015): Ideas about naturalness in public and political debates about science, technology and medicine: Analysis paper. Nuffield Council on Bioethics.

Nelson E. (1977): "Internal set theory: A new approach to nonstandard analysis." A Bulletin of American Mathematical Society 83 (6): 1165-1198.

Robinson, A. (1966): Non-Standard Analysis. North-Holland Publishing, Amsterdam.

Romportl, J. (2016): "Polomnožiny a emergence v umělé inteligenci." (English resume: "Semisets and Emergence in Artificial Intelligence”) Filosofický časopis / Philosophical Journal 64 (4): 587-599. Available at: http://filcasop.flu.cas.cz/index. php?id $=$ casopis\&cislo $=4-2016 \&$ obsah $=735$.

Savulescu, J. \& Maslen, H. (2014): "Moral enhancement and artificial intelligence: Moral AI?” In Beyond Artificial Intelligence: The Disappearing Human-Machine Divide, eds. J. Romportl, E. Zackova \& J. Kelemen, volume 9 of Topics in Intelligent Engineering and Informatics, Springer, 2014, pp. 79-93.

Silberstein, M. (2001): “Converging on emergence: Consciousness, causation and explanation." Journal of Consciousness Studies 8 (9-10): 61-98.

Smajdor, A. (2015): "Naturalness and unnaturalness in contemporary bioethics.” Technical report, Nuffield Council on Bioethics.

Tse, W. S. \& Bond, A. J. (2002): "Serotonergic intervention affects both social dominance and affiliative behaviour." Psychopharmacology 161 (3): 324-330. 
Vopěnka, P. (1979): Mathematics in the Alternative Set Theory. Teubner-Verlag, Leipzig.

Vopěnka, P. (1989): Úvod do matematiky v alternatívnej teórii množín. Alfa, Bratislava.

Vopěnka, P. (1996): Calculus Infinitesimalis, Pars prima. Práh, Praha.

Vopěnka, P. (2001): Meditace o základech vědy. Práh, Praha.

Vopěnka, P. (2012): The Great Illusion of 2oth Century Mathematics and Its New Foundations. University of West Bohemia, Plzeň.

Vopěnka, P. (2014): Al'ternativnaja teorija mnozhestv. Izdatel'stvo Instituta matematiki, Novosibirsk.

Vopěnka, P. (2015): Nová infinitní matematika I.-IV. Karolinum, Praha.

Vopěnka, P. (2019): New Infinitary Mathematics. Pending publication.

\section{Abstrakt \\ Přrirozenost a umělost uchopená pomocí přirozeného nekonečna}

Diskuze o přirozenosti, umělosti a nepřirozenosti v tomto článku jsou motivovány oblastí tzv. Human Cognitive Enhancement (HCE), čili technologickým vylepšováním kognitivních schopností člověka. Důvodem je potenciální schopnost HCE výrazně měnit a zasahovat do lidské osobnosti a identity. Článek nejprve navrhuje koncept lidské přirozenosti jako interakci mezi fysis a logos. Poté předkládá rámec pro intuitivní porozumění přirozenosti jako inherentní neschopnost jazyka plně popsat všechny vlastnosti objektu, který je přirozený. Analytické jádro článku pak navrhuje formální model přirozenosti založený na Vopěnkově fenomenologicky zakotvené alternativní teorii množin, jež je zde zároveň i stručně představena. Přirozenost a umělost jsou modelovány jako dvě strukturně odlišné přirozeně nekonečné polomnožiny $\mathrm{v}$ rámci alternativní teorie množin. Tato klíčová strukturní odlišnost je následně analyzována a aplikována zpět na problém HCE.

Klíčová slova: přirozenost, umělost, nekonečno, logos, fysis, filozofie jazyka, vylepšování kognitivních schopností, alternativní teorie množin, polomnožina, bioetika

Romportl, J. (2019): „Naturalness and Artificiality Revisited Through Natural Infinity.“ Filosofie dnes 11 (2): 4-33. Dostupné z www.filosofiednes.ff.uhk.cz 